\title{
Serum Level of Antibodies (IgG, IgM) Against Benzo[a]pyrene-7,8-diol-9,10-epoxide-DNA Adducts in Children Dermatologically Exposed
} to Coal Tar

\author{
Pavel Borský ${ }^{1}$, Ctirad Andrýs ${ }^{2}$, Jan Krejsek², Květoslava Hamáková3, Jan Kremláček ${ }^{5}$, Andrea Málková1, \\ Lenka Bartošová ${ }^{1}$, Zdeněk Fialaํ, Vladimír Palička ${ }^{4}$, Lenka Borská5,*
}

\begin{abstract}
Crude coal tar (CCT) contains polycyclic aromatic hydrocarbons (PAHs). Benzo[a]pyrene $(\mathrm{BaP})$ is metabolized into a highly reactive metabolite benzo[a]pyrene-7,8-diol-9,10-epoxide (BPDE) that is able to bind to DNA and creates BPDE-DNA adducts. Adducted DNA becomes immunogenic and induces immune response by production of antibodies against BPDE-DNA adducts (Ab-BPDE-DNA). Circulating Ab-BPDE-DNA was proposed as potential biomarker of genotoxic exposure to BaP (PAHs). Goeckerman therapy (GT) of psoriasis uses dermal application of CCT ointment (PAHs). In presented study (children with psoriasis treated by GT; $n=19$ ) the therapy significantly increased the level of Ab-BPDE-DNA (EI = 0.29/0.19-0.34 vs. 0.31/0.25-0.40; median/lower-upper quartile; $p<0.01$ ). The results support the idea of Ab-BPDE-DNA level as a possible tentative indicator of exposure, effects and susceptibility of the organism to the exposure of $\mathrm{BaP}$ (PAHs).
\end{abstract}

\section{KEYWORDS}

polycyclic aromatic hydrocarbons; coal tar; BPDE-DNA adducts; antibodies; psoriasis; goeckerman therapy; children

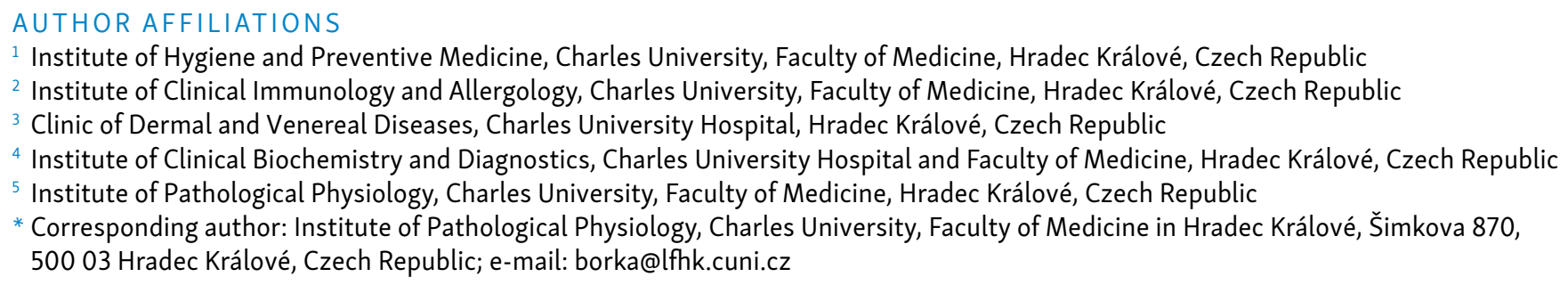




\section{INTRODUCTION}

Psoriasis is a multifactorial, chronic inflammatory skin disease, which often breaks out during childhood. Although the incidence of childhood psoriasis is unknown, some studies indicate that the first sign of psoriatic symptoms occurs in infants, children, and adolescents $(1,2)$. It is estimated that $30-50 \%$ of adults with psoriasis develop the condition before the age of 20 years (2). Psoriasis can adversely affect the quality of life (3) and represents the top 10 skin diagnoses in children (4).

Children are more susceptible to genotoxic effects of environmental exposures and medical treatments than adults because their organism is still developing (5). Recent trends in childhood cancers in the USA and Europe seem to confirm children's increased exposures to genotoxic/carcinogenic substances (6).

Goeckerman therapy (GT) represents a treatment of plaque psoriasis in children (7). The therapy combines dermal exposure of crude coal tar (CCT) ointment and UV radiation (UVR) (7-12). It seems that fundamental mechanism of therapeutic effects of CCT is based on immunosuppression induced by polycyclic aromatic hydrocarbons in coal tar (PAHs) without signs of systemic immuno-toxicity $(9,12)$. Retrospective studies have demonstrated that GT is effective in children and adolescents with moderate to severe psoriasis (7-12). However, the use of GT has recently decreased for several reasons, including a supposed genotoxicity of CCT/PAHs (13-14).

Several PAHs are recognized as potential environmental mutagens and carcinogens requiring bioactivation (15). Typical representative of PAHs, benzo[a]pyrene $(\mathrm{BaP})$, is bioactivated (metabolized) into a highly reactive genotoxic metabolite, benzo[a]pyrene-7,8-diol-9,10-epoxide (BPDE), which is able to bind to DNA or proteins and create corresponding BPDE-DNA or BPDE-protein adducts (14). Increased levels of BPDE adducts indicate recent genotoxic exposure to $\mathrm{BaP}$ (5). Cigarette smoke contains PAHs (including $\mathrm{BaP}$ ) and this way contributes to the total level of BPDE and related adducts in smokers (16).

Adducted DNA becomes immunogenic and induces immune response by production of antibodies against BPDE-DNA adducts (Ab-BPDE-DNA). Circulating Ab-BPDEDNA have been found in the serum of persons exposed to $\mathrm{PAHs} / \mathrm{BaP}$ (occupational exposures, smokers) $(17,18)$ and subsequently they were proposed as a potential biomarker of genotoxic exposure to $\mathrm{BaP}$ (PAHs) $(19,20)$. The number of studies dealing with this biomarker is relatively small and its practical use is still associated with uncertainties. Those are associated with individual factors, which are still largely unidentified (20). In order to contribute to reduction of the uncertainties, the presented study describes level of Ab-DNA-BPDE in the group of children dermally exposed to PAHs.

\section{MATERIALS AND METHODS}

\section{STUDY GROUP}

Basic characteristics of the study group were described in our previous work (8). Briefly, the group was formed of children with chronic stable plaque psoriasis, treated by GT at the Clinic of Dermal and Venereal Diseases, University Hospital, Hradec Králové (Czech Republic). Over the period of two years, we collected the data of 19 children (12 girls and 7 boys; average age of 12 years; range 5-17 years). Patients' exposure history to PAHs (including smoking) was checked by the questionnaire and patients who admitted previous significant exposure were excluded from the monitored group. The study was approved by the Ethics Committee of the University Hospital in Hradec Králové, Czech Republic. Informed written consent was obtained from the parents of each patient.

\section{GOECKERMAN THERAPY (GT)}

Detailed treatment procedure and the content of 16 selected PAHs in dermatological CCT were described previously (8). The therapy was based on daily application of dermatological ointment, containing $3 \%$ of CCT. According to the extent of lesions, $17-40 \%$ of the total body surface was covered by CCT ointment. Simultaneously, the patients were daily whole-body irradiated by UVR. Duration of the treatment was modified according to its effectiveness (average duration of 18 days; range 14-22 days). The effectiveness of the therapy was expressed by PASI score (Psoriasis Area and Severity Index) (21).

\section{SERUM LEVEL OF AB-BPDE-DNA}

The samples of heparinized venous blood were collected by venipuncture of the cubital vein before the first treatment and again after the total completion of GT. The obtained serum samples were stored in under $-70^{\circ} \mathrm{C}$ until they were analyzed. The level of Ab-BPDE-DNA (IgG, IgM) was determined by ELISA method. The results were expressed as the Evaluation Index (EI = absorbance of evaluated serum / absorbance of high positive control serum). Samples with EI less than 0.5 were termed as the serum with low level of Ab-BPDE-DNA. Analogously, the serum samples with EI greater than 0.5 were referred to as the serum with high level of Ab-BPDE-DNA (ELISA-VIDITEST anti-BPDE-DNA human, VIDIA, Jesenice, Czech Republic).

\section{STATISTICAL ANALYSIS}

The data were analyzed by using MATLAB rel. 2014b software (Mathworks, Inc., Massachusetts, USA). Because the Lilliefors test of normality had rejected the hypothesis of normal distribution, the nonparametric tests were used. Data were analyzed by the Wilcoxon signed rank test. The association between the serum level of Ab-BPDE-DNA after the therapy and the selected parameters was evaluated by Spearman rank Order Correlations.

\section{RESULTS}

In the group of children with psoriasis, dermatologically exposed to coal tar (within the GT) we evaluated the efficacy of the therapy and observed the level of Ab-BPDEDNA. Smoking was reported by five patients. The number 

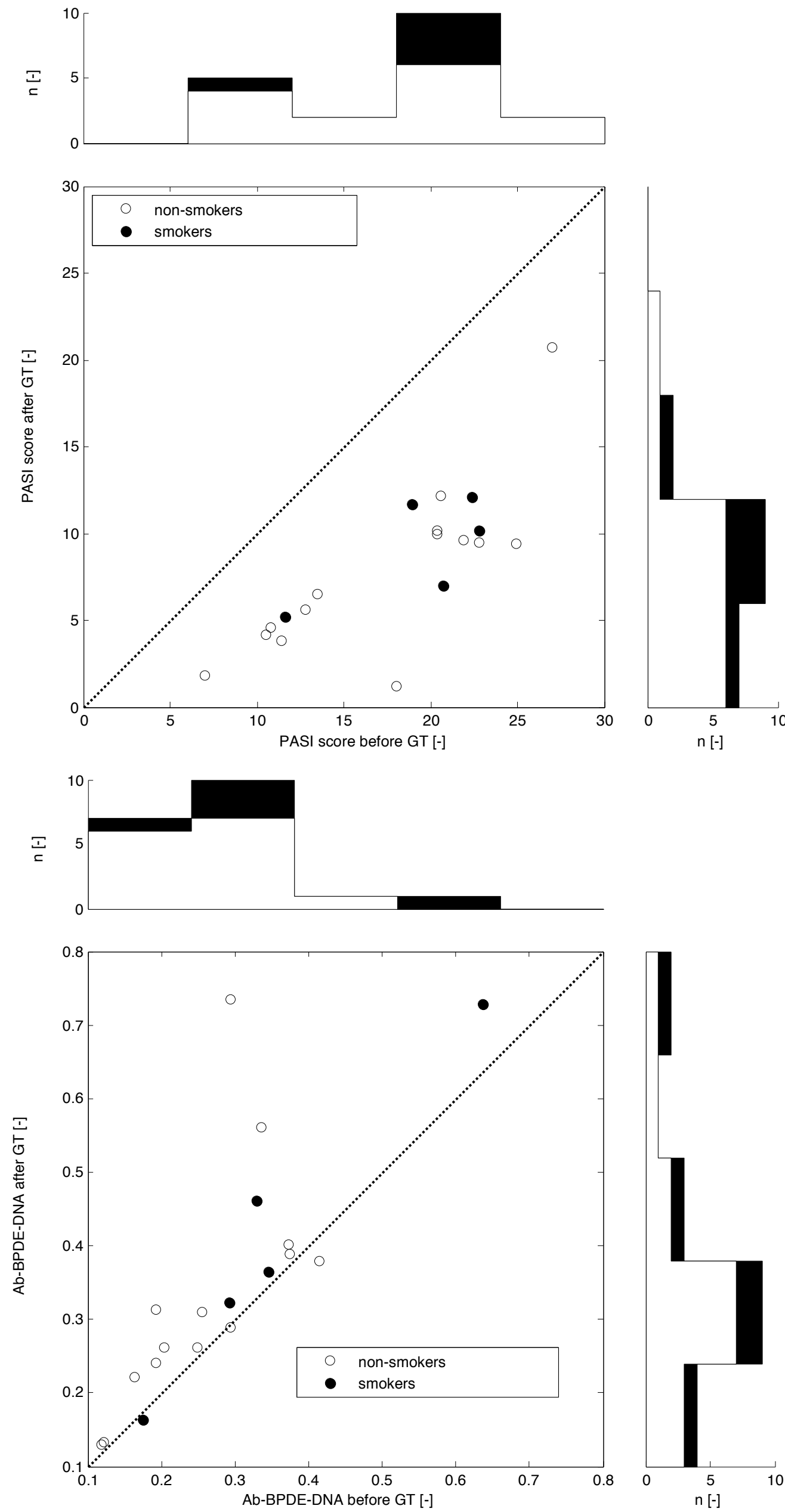

Fig. 1: The levels of PASI score. Legend: The levels are dimensionless. Scatter plot depicts PASI score before and after the GT therapy. Altogether 19 dots represent 38 measurements each dot belongs to one patient. The top histogram shows data distribution before treatment, the right side histogram corresponds to the after treatment values distribution. The white zones represent non-smokers data, and the black zones depict smokers' ones.

Fig. 2: The levels of Ab-BPDE-DNA. Legend: The levels are dimensionless (EI). Scatter plot depicts Ab-BPDE-DNA before and after the GT therapy. Altogether 19 dots represent 38 measurements, each dot belongs to one patient. The top histogram shows data distribution before treatment, the right side histogram corresponds to the after treatment values distribution. The white zones represent nonsmokers data, and the black zones depict smokers' ones. 
of smoked cigarettes was overall low, irregular and ranged from one to four cigarettes per "normal" day (outside the hospital). During hospitalization, they almost did not smoke at all. Due to the low number of patients, the group of "smokers" was not statistically evaluable. Therefore, the statistical evaluation was performed only for the whole group of respondents (see below).

The therapy was highly effective because the PASI score significantly decreased (20.4/11.9-22.3 vs. 9.4/4.8-10.2; median/lower-upper quartile; $\mathrm{n}=19 ; \mathrm{p}<0.001$ ) (Fig. 1).

After the therapy we found significantly increased serum level of Ab-BPDE-DNA ( $E I=0.29 / 0.19-0.34 \mathrm{vs}$. 0.31/0.25-0.40; median/lower-upper quartile; $\mathrm{n}=19$; $\mathrm{p}<0.01$ ) (Fig. 2). We did not find a significant relationship between the level of Ab-BPDE-DNA (after GT) and total duration of the therapy $(r=0.30)$, body surface area covered by CCT ointment $(r=0.02)$, total time of $U V$ radiation $(r=0.09)$ and PASI score $(r=0.21)$.

\section{DISCUSSION}

Genotoxic effects of chemical and physical factors have been studied largely in adult population, however only a limited number of studies have investigated genotoxic damage in children. It is rather surprising because children represent a population group with high sensitivity to chemical and physical factors. The studies suggest that early exposures during childhood can play an important role in the development of chronic diseases in adulthood: the earlier the exposure, the greater the risk of chronic disease, including cancer (22).

In our previous works, we studied genotoxic and immuno-toxic effects of combined exposure to PAHs and UVR on human organism. Monitored groups consisted of patients (men, women, and children) suffering from psoriasis treated by GT. In the groups of children, we found high degree of dermal absorption of PAHs (elevated levels of urinary 1-hydroxypyrene and hydroxylated phenanthrenes), elevated urinary mutagenicity (Ames test), and increased genotoxicity (chromosomal aberration in peripheral lymphocytes) $(8,10,11)$. In addition, we found an elevated level of cellular stress (heat shock proteins; Hsp70) (11), oxidative stress (8-hydroxy-2'-deoxyguanosine, 8-hydroxyguanosine and 8-hydroxyguanine), and BPDE-DNA adducts (8).

In the presented study, the serum level of Ab-BPDEDNA increased significantly $(p<0.01)$ after the therapy. However, it should be noted that the majority of Ab-BPDEDNA values (84\% of all samples) were found in the zone of low levels $(\mathrm{EI}<0.5)$. Three samples ranged in high values (EI > 0.5), whilst one of them was higher even before the treatment. Similar results were obtained in our previous study focused on the level of Ab-BPDE-DNA in two groups of adult patients with psoriasis, treated by GT (3\% and $5 \%$ CCT) (8). Other literary data concerning the levels of Ab-BPDE-DNA after therapeutic exposure to CCT are very limited and comparison with these data is complicated because of the use of different methodologies (23).
The term of biological monitoring includes markers of exposure, effect and susceptibility. Circulating AbBPDE-DNA signals the presence of genotoxic BPDE-DNA adducts in the organism. It means the level of Ab-BPDEDNA must be influenced by the same factors as the level of BPDE-DNA adducts, i.e., by the level of exposure to PAHs, by the individual character of BaP metabolism and by the degree of adaptation and reparation processes. In addition, the serum level of Ab-BPDE-DNA also reflects the immune status and a protective capacity of the immune system against $\mathrm{BaP}$ induced cancer (18).

The previous paragraphs suggest that the level of circulating Ab-BPDE-DNA could serve as a marker of exposure to PAHs. Elevation of exposure to PAHs increases both the level of BPDE adducts and the related level of Ab-BPDEDNA.

The BPDE-DNA adducts are assumed to be genotoxic and present a biological response of the organism to genotoxic exposure of PAHs. In this context, the level of AbBPDE-DNA can be considered a marker of genotoxic effect (marker of effect).

Finally, the Ab-BPDE-DNA level reflects individual character of metabolism (BaP), condition of adaptation and reparation processes, immune status and protective capacity of the immune system. All of these systems determine the level of individual susceptibility. For this reason, the level of Ab-BPDE-DNA can serve as a tentative marker of individual sensitivity to exposure to BaP.

Application of CCT (PAHs) increases the level of BPDE-DNA adducts and consequently increases the production of Ab-BPDE-DNA. However, PAHs have also an immunosuppressive effect and in this way they can reduce the production of Ab-BPDE-DNA. Therefore, the final level of Ab-BPDE-DNA is probably the result of these opposite processes. It seems likely that repeated or chronic exposure to PAHs (for instance, by occupational atmosphere or by smoking) reduces body immune response and presumably can reduce levels of anti-PAHs antibodies $(9,17)$. Described mechanisms may be one of the reasons why we found no significant association between the level of $\mathrm{Ab}$ BPDE-DNA and the characteristics of exposure (particularly the duration and the extent of exposure).

We found only few epidemiological studies of PAHs exposed population to assess the impact of carcinogen-specific antibodies on the risk of tumor development and on the relation to other indicators of genotoxic exposure (17, $18,20)$. Few attempts have also been made, both in vivo and in vitro, to understand the implications of an antibody response to metabolic activation of carcinogens and carcinogenesis $(24,25)$. Recent study provided the evidence that specific humoral immunity might modulate the genotoxic effect induced by subsequent carcinogen exposure, however, the mechanisms involved remain largely unexplored (19).

GT is an effective treatment for moderate and severe psoriasis in children (7-12). In this study, the high effectiveness of the therapy was confirmed by a significant decrease of the PASI score. 


\section{CONCLUSION}

The results of presented study support the idea of Ab-BPDE-DNA level as a possible tentative indicator of exposure, effects and susceptibility of an organism to the exposure of BaP (PAHs).

\section{ACKNOWLEDGEMENTS}

Supported by Charles University, Faculty of Medicine in Hradec Králové, Czech Republic, project PROGRES Q40-09, Q40-10. Acknowledgement to Dana Knajflová for text proofreading and linguistics.

\section{CONFLICT OF INTEREST}

None declared.

\section{APPROVAL AND INFORMED CONSENT}

The study was approved by the Ethics Committee of the University Hospital in Hradec Králové, Czech Republic. Informed written consent was obtained from each patient.

\section{REFERENCES}

1. Lysell J, Tessma M, Nikamo P, et al. Clinical Characterisation at Onset of Childhood Psoriasis - A Cross Sectional Study in Sweden. Acta Derm Venereol 2015; 95: 457-461.

2. Matusiewicz D, Koerber A, Schadendorf D, et al. Childhood psoriasis - an analysis of German health insurance data. Pediatr Dermatol 2014; 31: 8-13.

3. Kim GE, Seidler E, Kimball AB. Effect of Age at Diagnosis on Chronic Quality of Life and Long-Term Outcomes of Individuals with Psoriasis. Pediatr Dermatol 2015; 32: 656-662.

4. Kakande B, Gumedze F, Hlela C, et al. Focus on the Top Ten Diagnoses Could Reduce Pediatric Dermatology Referrals. Pediatr Dermatol 2016; 33: 99-102

5. Sram RJ, Binkova B, Dostal M, et al. Health impact of air pollution to children. Int J Hyg Environ Health 2013; 216: 533-540.

6. Neri M, Ugolini D, Bonassi S, et al. Children's exposure to environmental pollutants and biomarkers of genetic damage. II. Results of a comprehensive literature search and meta-analysis. Mutat Res 2006; 612: 14-39.

7. Kortuem KR, Davis MD, Witman PM, et al. Results of Goeckerman treatment for psoriasis in children: a 21-year retrospective review. Pediatr Dermatol 2010; 27: 518-524.

8. Borska L, Andrys C, Krejsek J, et al. Oxidative Damage to Nucleic Acids and Benzo(a)pyrene-7,8-diol-9,10-epoxide-DNA Adducts and Chromosomal Aberration in Children with Psoriasis Repeatedly Exposed to Crude Coal Tar Ointment and UV Radiation. Oxid Med Cell Longev 2014; ID302528: 1-10a.

9. Borska L, Andrys C, Krejsek J, et al. Serum level of antibody against
benzo[a]pyrene-7,8-diol-9,10-epoxide-DNA adducts in people dermally exposed to PAHs. J Immunol Res 2014; ID834389: 1-6b.

10. Borska L, Smejkalova J, Cerna M, et al. Urinary mutagenicity and genotoxic risk in children with psoriasis after therapeutic exposure to polycyclic aromatic hydrocarbons and ultraviolet radiation. Mutat Res 2010; 696: 144-147.

11. Borska L, Andrys C, Krejsek J, et al. Genotoxic hazard and cellular stress in pediatric patients treated for psoriasis with the Goeckerman regimen. Pediatr Dermatol 2009; 26: 23-27.

12. Borska L, Fiala Z, Krejsek J, et al. Immunologic changes in TNF-alpha, sE-selectin, sP-selectin, sICAM-1, and IL-8 in pediatric patients treated for psoriasis with the Goeckerman regimen. Pediatr Dermatol 2007; 24: 607-612.

13. Paghdal KV, Schwartz RA. Topical tar: back to the future. J Am Acad Dermatol 2009; 61: 294-302.

14. Roelofzen JH, Aben KK, Van de Kerkhof PC, et al. Dermatological exposure to coal tar and bladder cancer risk: A case-control study. Urol Oncol 2015; 33: 19-22.

15. Roelofzen JH, van der Valk PG, Godschalk R, et al. DNA adducts in skin biopsies and 1-hydroxypyrene in urine of psoriasis patients and healthy volunteers following treatment with coal tar. Toxicol Lett 2012; 213: 39-44.

16. Lee BK, Chung MY, Lee KW. Benzo[a]pyrene-7,8-diol-9,10-epoxide inhibits gap junction intercellular communication via phosphorylation of tumor progression locus 2 in WB-F344 rat liver epithelial cells. Mol Carcinog 2015; 54: 351-358.

17. Pauk N, Klimesova S, Kara J, et al. The relevance of monitoring of antibodies against the polycyclic aromatic hydrocarbon (PAH) and PAH-DNA adducts in serum in relation to lung cancer and chronic obstructive pulmonary disease (COPD). Neoplasma 2013; 60: 182-187.

18. Petruzzelli S, Celi A, Pulerà N, et al. Serum antibodies to benzo(a) pyrene diol epoxide-DNA adducts in the general population: effects of air pollution, tobacco smoking, and family history of lung diseases. Cancer Res 1998; 58: 4122-4126.

19. Pavanello S, Dioni L, Hoxha M, et al. Mitochondrial DNA copy number and exposure to polycyclic aromatic hydrocarbons. Cancer Epidemiol Biomarkers Prev 2013; 22: 1722-1729.

20. Galati R, Zijno A, Crebelli R, et al. Detection of antibodies to the benzo(a)pyrene diol epoxide-DNA adducts in sera from individuals exposed to low doses of polycyclic aromatic hydrocarbons. J Exp Clin Cancer Res 2001; 20: 359-364.

21. Chow C, Simpson MJ, Luger TA, et al. Chubb H, Ellis CN. Comparison of three methods for measuring psoriasis severity in clinical studies (Part 1 of 2): change during therapy in Psoriasis Area and Severity Index, Static Physician's Global Assessment and Lattice System Physician's Global Assessment. J Eur Acad Dermatol Venereol 2015; 29: 1406-1414.

22. Feretti D, Ceretti E, De Donno A, et al. Monitoring air pollution effects on children for supporting public health policy: the protocol of the prospective cohort MAPEC study. BMJ Open 2014; 4: e006096.

23. Santella RM, Perera FP, Young TL, et al. Polycyclic aromatic hydrocarbon-DNA and protein adducts in coal tar treated patients and controls and their relationship to glutathione S-transferase genotype. Mutat Res 1995; 334: 117-124.

24. Saladi R, Austin L, Gao D, et al. The combination of benzo[a]pyrene and ultraviolet A causes an in vivo time-related accumulation of DNA damage in mouse skin. Photochem Photobiol 2003; 77: 413-419.

25. Wani MA, El-Mahdy MA, Hamada FM, et al. Efficient repair of bulky anti-BPDE DNA adducts from non-transcribed DNA strand requires functional p53 but not p21(waf1/cip1) and pRb. Mutat Res 2002; 505: $13-25$. 